\title{
Characteristics and controlling factors of the drought runoff coefficient
}

\author{
Rei Itsukushima ${ }^{1}$
}

${ }^{1}$ Department of Transdisciplinary Science and Engineering, Tokyo Institute of Technology, 4259 G5-4 Nagatsuta-cho, Midori5 ku, Yokohama 226-8502, Japan

Correspondence to: Rei Itsukushima (itsukushima.r.aa@m.titech.ac.jp)

\begin{abstract}
Increasing water demand due to population growth and economic development or changes in rainfall pattern as a result of climate change is likely to alter the duration and magnitude of droughts. To establish sustainable water resource management based on changes in future drought risk, understanding the relationship between low-flow conditions and controlling factors relative to drought magnitude is important. This study is the first attempt at revealing the relationship between low-flow and controlling factors at differing drought severities. I calculated the drought runoff coefficient for six types of occurrence probability based on past observation data of minimum flow and precipitation. Furthermore, I investigated the pattern of change in the drought runoff coefficient in accordance with the occurrence probability and relationship between the coefficient and geological, land use, and topographical factors. The drought runoff coefficient for multiple drought magnitudes exhibited three behaviour types corresponding to precipitation pattern. The results from a generalized linear model (GLM) revealed that the controlling factors differ depending on drought magnitude. In high-frequency drought, the drought runoff coefficient was influenced by geological and vegetation factors, whereas land use and topographical factors influenced the drought runoff coefficient in low-frequency drought. These differences were caused by differences in the runoff component, which dominates stream discharge according to drought magnitude. Therefore, for effective water resource management, estimation of the drought runoff volume needs to consider precipitation pattern, geology, land use, and topography.
\end{abstract}

\section{Introduction}

The causes of, and adaptations to, droughts as natural disaster have been researched from the perspective of hydrology, environmentology, geology, meteorology, and agronomy (Mishra \& Singh, 2010). The causes of droughts have been investigated in various regions, by focusing on rainfall pattern (Verschuren et al., 2000; Tabari, et al., 2012; Tfwala et al.,

25 2018), temperature (Nicholls, 2004; Hein et al., 2019), wind (Namias, 1989), and humidity (Behrangi et al., 2015). In addition to the impacts of natural factors, aggravation of the drought hazard is expected to occur because of growing water demand associated with population growth and economic development (Frederiksen, 1996; Xiao-jun et al., 2012; El Kharraz et al., 2012) and changes in the hydrological cycle associated with anthropogenic impacts such as land use change (Liu et al., 2017; Deo et al., 2009; Lee et al., 2011). 
Droughts are generally categorized into four types (Wilhite \& Glantz, 1985). First, drought resulting from precipitation shortage is defined as meteorological drought (Mishra \& Singh, 2010; Smakhtin \& Hughes, 2007). In addition, the relationship between monthly rainfall and cumulative precipitation amount was investigated (Eltahir, 1992). Second, a shortage of surface or subsurface water in relation to water utilization, as determined by established water resource management, is defined as hydrological drought (Tallaksen \& Van Lanen, 2004; Nalbantis \& Tsakiris, 2009). Stream water discharge is often used as an indicator of the management and analysis of hydrological drought (Clausen \& Pearson, 1995). Third, agricultural drought indicates declining soil moisture, regardless of surface water resources, causing crop failure (Rickard, 1960; Nieuwolt, 1986). Finally, socio-economic drought occurs in cases of defectiveness and incompatibility of the water resource system in relation to water demand (Eklund \& Seaquist, 2015; Mehran et al., 2015).

Prolonged droughts cause severe socio-economic loss (Carrão et al., 2018; Ahmadalipour et al., 2019). Research results on the evaluation of the economic loss of droughts indicate that damage of \$6-8 billion per year occurs in the United States (Smith \& Katz, 2013; Smith \& Matthews, 2015), with the EU suffering damages of $€ 100$ billion over the last 30 years (Carrão et al., 2016). The human damage caused by drought is even more serious. Droughts in Ethiopia/Sudan (1984) and the Sahel region (1974) killed 450,000 and 325,000 people, respectively (Vicente-Serrano et al., 2012).

In addition, changes in the hydrological cycle as a result of climate change are expected to increase extreme drought events (Mishra \& Singh, 2010). Unlike flood disasters, the influence of climate change on drought is not yet fully understood. However, future prediction of drought aggravation due to population growth in central Africa (Ahmadalipour et al., 2019) and increasing drought duration and severity in the interior southwest of the United States (Andreadis \& Lettenmaier, 2006) have been reported. Furthermore, forecasts of drought using soil moisture as an indicator have indicated increasingly frequent drought events in Europe regardless of emission scenario (Grillakis, 2019).

Stream flow discharge is an important indicator of hydrological drought because in many regions water resources are obtained from surface water. Previous studies of stream discharge have focused on water resources, ecosystems, river channel formation, and flood management. In particular, the effects of flow regime alteration on ecosystems have been studied (Sparks, 1995; Bunn \& Arthington, 2002; Taylor et al., 2008), and the natural flow regime has been elucidated (Poff et al., 1997; Lytle \& Poff, 2004; Naiman et al., 2008; Kennard et al., 2010). Research on the factors that influence flow discharge have focused on rainfall amount or pattern (Obled et al., 1994; Montgomery et al., 1997), land use (Kashaigili, 2008; McIntyre \& Marshall, 2010), and watershed geology (Meijerink, 1985). For research on flow regime, the factors influencing low flows strongly related to drought have been investigated, through focusing on watershed area, watershed elevation, ratio of urban area or forest cover, and geology (Mushiake et al., 1981; Zecharias \& Brutsaert, 1988; Vogel \& Kroll, 1992). However, these studies mainly focused on mountainous watersheds or a single factor. In addition, the low flows prevalent in the above research were 60 not probabilistically evaluated. Therefore, the relationship between the appearance frequency of low flow and its controlling factors remain unknown.

Increasing water demand due to population growth and economic development and/or changes in rainfall pattern due to climate change alter the duration and magnitude of droughts. To establish sustainable water resource management based on 
changes in future drought risk, understanding the relationship between low flow and its controlling factors in relation to the magnitude of drought is important. Based on the above, I formulated the hypothesis that the controlling factors of low surface flow vary according to drought severity. The present study is a first attempt at revealing this relationship. The surface water volume of each drought occurrence probability was calculated based on long-term observation data. The relationship between the drought water volume of each occurrence probability and the controlling factors was analyzed. Multiple controlling factors related to geology, land use, and topography were introduced. Since the research results identify the controlling factor of drought for each occurrence probability, they may contribute to the development of effective water resource management through prediction of drought water volumes or impacts of climate change on the surface water runoff.

\section{Materials and Methods}

\subsection{Location of the study area}

In this study, 44 watersheds belonging to the Japanese archipelago where discharge observations have been conducted over

7530 years were used. To extract stations where the impact of flow regime regulation due to a dam is small, observation stations whose watershed was subject to over $10 \%$ occupancy by a dam watershed were excluded (Fig. 1). The watershed areas ranged from 47 to $8,208 \mathrm{~km} 2$.

\subsection{Calculation of the hydrological data}

Annual total discharge of each watershed was obtained from the Water Information System (http://www1.river.go.jp/). A 80 sample of annual total discharge of each observation point was statistically calculated to estimate the total discharge for occurrence probabilities of 2, 10, 30, 50, 100, and 400 years. Hydrological Statistics Utility (ver. 1.5.) was used for the statistical analysis. I calculated the estimated design magnitude using 13 probability distributions including the exponential distribution (EXP), Gumbel distribution (Gumbel), exponential-type distribution of maximum (SqrtEt), generalized extreme value distribution (Gev), log-Pearson type III distribution (real coordinate space) (LP3Rs), log-Pearson type III distribution

85 (log coordinate space) (LogP3), Iwai method (Iwai), Ishihara Takase method (IshiTaka), the logarithmic normal distribution with three parameters (quantile method) (LN3Q), the logarithmic normal distribution with three parameters (Slade II) (LN3PM), the logarithmic normal distribution with two parameters (Slade I, L-moments method) (LN2LM), the logarithmic normal distribution with two parameters (Slade I, moments method) (LN2PM), and the logarithmic normal distribution with four parameters (Slade IV, moments method) (LN4PM). Among the 13 probability distributions, the estimated design magnitude was selected based on standard least squares criteria (Takasao et al., 1986).

Annual precipitation data were obtained from the database of the Japan Meteorological Agency (http://www.jma.go.jp/jma/index.html). Data from observation stations with an observation period of over 30 years were used. A sample of the average depth of rainfall over the watershed area was calculated using a Voronoi diagram. The estimated 
annual precipitation for occurrence probabilities of 2, 10, 30, 50, 100, and 400 years was calculated using the same method used for annual total discharge.

The drought runoff coefficient of each occurrence probability for the 44 watersheds was calculated by dividing the annual total discharge by annual precipitation.

\subsection{Collecting data for controlling factors}

I assessed 11 indicators, classified into three categories (geological, land use, and topographic factors), as controlling factors of the drought runoff coefficient.

As a geological factor, I focused on surface geology. I classified the surface geology into four groups (volcanic rock, plutonic rock, metamorphic rock, and sedimentary rock) based on geological creation processes using a subsurface geological map with a scale of 1:200,000 (http://nrb-www.mlit.go.jp/kokjo/inspect/landclassification/download/). The ratio of each surface geology was calculated using a geographic information system (GIS). In addition, metamorphic rock was excluded from the analysis because the composition ratio was less than $5 \%$ in all target watersheds.

The land use data were obtained from the National Survey on the Natural Environment by the Japan Ministry of Environment (http://www.vegetation.biodic.go.jp/legend.html). Classification of land use was based on five categories (coniferous forest, broadleaf forest, mixed coniferous-broadleaf forest, cropland, and urban areas); each class was considered to have different effects on runoff phenomena. The ratio of each land use for the 44 watersheds was calculated by GIS.

I calculated the inverse of channel slope and topographical gradient, form ratio, and roundness as topographic factors. Channel slope was defined as the division of the difference in elevation between the observation station and the headwater by the length of the stream channel. The form ratio was calculated by dividing the watershed area by the square of the length of the stream channel (Horton, 1932). The form ratio approaches 1.0 if the shape of the basin is almost square or circular. The roundness was calculated as the division of the circumference of the same area of a watershed by the boundary length of the watershed (Miller, 1953). Topography data were obtained from Global 3D Map Service (ALOS World 3D-30 m).

\subsection{Statistical analysis}

To investigate the characteristics of the drought runoff coefficient and its relationship with the controlling factors, an analysis by non-metric multi-dimensional scaling (NMDS) (Kruskal, 1964) was conducted. NMDS refers to a family of related ordination techniques, all of which use rank order information in a (dis)similarities matrix (Coxon, 1982; Gauch, 1982; Whittaker, 1987). Similarity in the drought runoff coefficient between watersheds was calculated by Bray-Curtis similarity (Bray \& Curtis, 1957). As a result of the permutation test, controlling factors closely related to the classification of the drought runoff coefficient $(\mathrm{p}<0.01)$ were presented as vectors. Of the 11 indicators used as controlling factors, the topographical gradient was excluded from the analysis because of the strong positive correlation $(\mathrm{r}>0.07)$ between it and cropland. In addition, to investigate the difference in controlling factors among groups classified by similarity of the drought runoff coefficient, the controlling factors of each group were analyzed using one-way analysis of variance and the Kruskal-Wallis 
test. Further, Tukey's honestly significant difference (Tukey's HSD) and the Steel-Dwass test were conducted to reveal differences between groups if a significant difference was confirmed among groups.

Next, a generalized linear model (GLM) was developed to formulate a prediction model for the drought runoff coefficient for each occurrence probability. As the explanatory variables, 10 controlling factors were selected, same of the NMDS. The GLM is an extinction model of a linear model, which allows the incorporation of non-normal distributions of the response variables and linear transformations of the dependent variables (McCullagh and Nelder, 1989). I compared the obtained Akaike information criteria (AIC) (Burnham \& Anderson, 2002) of each model by increasing and decreasing the variables. Finally, I adopted the lowest AIC model as the best model for each of the species. GLM was conducted using MASS (Version 7.3-50).

\section{Results}

\section{3.1 Annual precipitation and drought water volume for each occurrence probability}

The calculation results for annual precipitation, drought runoff volume, and drought water volume per unit drainage area for each occurrence probability are presented in Table 1 . The precipitation amount and drought water volume per unit drainage area tended to be high in southwest Japan and low in north Japan. In addition, the differences in precipitation amount and drought water volume per unit drainage area between observation stations tended to decrease, corresponding with the increasing occurrence probability. Eight types of probability distribution were selected for the calculation of drought water volume. The probability distributions indicated highest adaptability for Gev, which was selected at 23 stations. LN3Q had the second highest adaptability, being selected at seven stations. In the calculation of the precipitation amount, 10 types of probability distribution were selected. Adaptability followed was in the order: Gev (16 stations) > Gumbel (7 stations) > LN3Q (6 stations).

\section{3.2 Classification of the drought runoff coefficient and controlling factors}

As a result of seriation and clustering using the drought runoff coefficient for each occurrence probability based on NMDS, the 44 stations were classified into three groups. Furthermore, SR and PR (geological factors) and CF, MCBF, UA, and CL (land use factors) were selected as the controlling factors strongly related to the classification of the drought runoff coefficient based on the permutation test $(\mathrm{p}<0.01)$. The selected controlling factors were placed in the positive direction of the first axis for PR and UA. MCBF was placed in the negative direction of the first axis. CL was placed in the positive direction of the second axis. CF and SR were placed in the negative direction of the second axis (Fig. 2).

Group A $(\mathrm{N}=16)$ was located in the second and third quadrats, composed of watersheds dominated by a mixed coniferous and broadleaf forest. The watersheds belonging to Group A were also characterized by low ratios of urban area and plutonic rock. Group B $(\mathrm{N}=16)$ was located in the first and fourth quadrats, composed of watersheds dominated by urban area or

155 cropland. The surface geology of watersheds belonging to Group B was dominated by plutonic rock. Group C $(\mathrm{N}=12)$ was located in the third and fourth quadrats, composed of watersheds characterized by a high ratio of the coniferous forest. 
The average value of the drought runoff coefficient for each occurrence probability was large, with Group A > B > C. In addition, the difference in the drought runoff coefficient between occurrence probabilities was smaller in Group A than other groups, exhibiting a little difference between the occurrence probabilities of 2 and 400 years. However, in Group C, the drought runoff coefficient tended to decrease in accordance with the increasing occurrence probability. In Group B, the change in drought runoff coefficient with occurrence probability indicated behavior intermediate between Groups A and C. Although the drought runoff coefficient decreased up to an occurrence probability of 30 years, it had an almost constant value at occurrence probabilities exceeding 30 years (Fig. 3).

\subsection{Characteristics of controlling factors in each group}

Fig. 4 presents a boxplot of the controlling factors for each group. The bold line in the center of the boxplot depicts the median of the data. The top and bottom of the box indicate the third and first quartiles, respectively. In addition, the line located at the top of the box indicates the largest value over than the value, calculated by (first quartile $-1.5 \times($ third quartile - first quartile)). The line located at the bottom of the box indicates the smallest value less than the value, calculated by (third quartile $-1.5 \times($ third quartile - first quartile) $)$.

Geological factors VR and SR had similar results. The highest values for both indicators were observed in Group A, followed by those in Group C and Group B. One-way analysis of variance indicated a significant difference among the three groups $(\mathrm{p}<0.01)$. The Tukey's HSD test revealed a significant difference between Group B and the other two groups ( $<$ 0.01) for both factors. However, PR had an opposite trend. The average value for PR was highest in Group B (41\%), followed by those in Group C (7.2\%) and Group A (2.7\%). Results of the Kruskal-Wallis test revealed significant differences among

175 the groups $(\mathrm{p}<0.01)$. In addition, the Steel-Dwass test revealed that the PR of Group B was significantly higher than that of Group A ( $\mathrm{p}<0.01)$ and Group C $(\mathrm{p}<0.01)$.

As for the land use factors, MCBF was only confirmed in the watersheds belonging to Group A. The average value for UA was highest in Group B (12\%), followed by those in Group C (6.4\%) and Group A (2.9\%). Results of the Kruskal-Wallis test revealed significant differences among the groups $(\mathrm{p}<0.01)$. In addition, the Steel-Dwass test revealed that the UA of Group A was significantly lower than that of Group B (p<0.01) and Group C (p < 0.05).

By contrast, one-way analysis of variance and the Kruskal-Wallis test indicated no significant difference for the land use factors $\mathrm{BF}, \mathrm{CF}$, and $\mathrm{CL}$ and all of the topographical factors.

\subsection{Relationship between the drought runoff coefficient for each occurrence probability and the controlling factor}

Analysis of the relationship between the drought runoff coefficient for each occurrence probability and the controlling factor by the GLM revealed that PR, SR, CF, and CL are decreasing factors for the drought runoff coefficient, whereas BF, $\mathrm{MCBF}$, and Gr are increasing factors. The influence of these controlling factors on the drought runoff coefficient differed among the occurrence probabilities. Indicators of the forest classification were selected as controlling factors for occurrence probabilities of 2 and 10 years, whereas the land use factor, CF, and UA were selected as decreasing factors for the drought 
runoff coefficient for occurrence probabilities of over 30 years. Goodness of fit was highest for the occurrence probability of 50 years $\left(R^{2}=0.444\right)$, and it was lowest for the occurrence probability of two years $\left(R^{2}=0.377\right)$. VR (geological factor) and FR and CLR (topographical factors) were not selected as controlling factors of the drought runoff coefficient (Table 2).

\section{Discussion}

\subsection{Difference in drought runoff coefficient between areas}

As a result of drought runoff coefficient classification, observation stations belonging to the Japanese archipelago were classified into three groups: Groups A, B, and C. The drought runoff coefficient of Group A was characterized by high values regardless of changes in occurrence probability. However, the drought runoff coefficient of Group C decreased with increasing occurrence probability. The change in the drought runoff coefficient with increasing occurrence probability for Group B had an intermediate trend between Groups A and C. The stable and high drought runoff coefficient of Group A, which was composed of watersheds belonging to the heavy snow area, can be attributed to its more particular precipitation pattern compared to those of other areas. Takahashi et al. (1978) investigated the drought water volume of this water source area and explained that the large drought water volume of north Japan results from the stable water supply induced by spring snowmelt runoff and intermittent rainwater in fall. This water supply contributes to maintaining the groundwater in the drought season. In addition, the drought risk of the area influenced by spring snowmelt runoff will increase owing to the decreasing precipitation amounts in winter and spring as caused by climate change. This suggests the importance of snowmelt runoff to water resource recharge (Wada et al., 2005).

A trend of decreasing drought runoff coefficient with increasing occurrence probability was found in Group C, which is composed of the southwest Japanese archipelago. In these watersheds, the precipitation amount largely depends on the concentrated rainfall of a typhoon or a rainy season (Arao \& Kaneko, 1985). Therefore, the low supply of water into the ground during drought results in a low drought runoff coefficient in the case of a high occurrence probability. In addition to the precipitation pattern, the geology of the watersheds belonging to Group $\mathrm{C}$ also seemed to influence the low drought runoff coefficient. Group C was composed of watersheds with a high ratio of sedimentary rock (Figure 4). Further, the geological age of the sedimentary rock of these watersheds (the Mesozoic and Paleozoic age) is older than that in other areas (Sudo, 2006). The low drought runoff coefficient was thought to be caused by the high agglomeration degree of the rock, which is a result of the high geological age influencing the deep percolation of precipitation.

\section{$215 \quad 4.2$ Controlling factors and the drought runoff coefficient}

\subsubsection{Occurrence probability of drought and controlling factors}

Based on the GLM, which investigated the relationship between the drought runoff coefficient and controlling factors, geological factors and land use factors (vegetation) influenced the drought runoff coefficient in high-frequency drought, 
whereas land use factors and topographic factors were selected as influencing factors in low-frequency drought. This is considered to be due to the fact that the runoff components that control flow discharge differ depending on drought frequency. In the case of high-frequency drought, the factors closely related to surface runoff or subsurface flow were selected, and factors related to the water-table stream with a larger time scale seemed to be selected for low-frequency drought. Previous research investigating the relationship between flood discharge and controlling factors for multiple occurrence probabilities revealed that a coniferous forest increases discharge in low-frequency floods, whereas topographical factors increase discharge in highfrequency floods (Itsukushima et al., 2016). In addition, it is reported that the controlling factor for stream discharge changes from rainfall to geological factors with threshold of ordinary water discharge (Mushiake et al., 1981). From these research results, it is clear that the controlling factors change according to the frequency of both flood and drought events.

\subsubsection{Geological factors and the drought runoff coefficient}

Some research has revealed that geology is one of the controlling factors of flow regime (Peters et al., 2003, 2005; Salinas

et al., 2013). The reasons for differences in drought runoff or base flow as a result of geology are that (i) the retention capacity of groundwater differs based on geology, and (ii) the infiltration capacity of soils differs based on geology (Lacey \& Grayson, 1998; Bloomfield et al., 2009). From the GLM, PR and SR (among the geological factors) were selected as controlling factors that decrease the drought runoff coefficient in high-frequency drought (Table 2). This result is incompatible with the research result of Mushiake et al. (1981), who noted that granite (classified as a plutonic rock) is a factor in increasing drought discharge.

235 This difference was caused by the location of the study area and the observation period of the data. Mushiake et al. (1981) used the average drought value based on a relatively short-term period. In addition, their research focused on a mountainous river, the drought discharge of which was dominated by surface runoff or subsurface flow. By contrast, Yokoo \& Oki (2010) revealed that geological age has a relation with drought runoff; in particular, based on an investigation of watersheds with an area of more than $100 \mathrm{~km} 2$, quaternary geology was found to be an increasing factor for drought runoff. Therefore, it is necessary for one to consider both geology type and geological age as indicators when one predicts drought runoff.

In addition to plutonic rock, sedimentary rock was selected as a decreasing factor for the drought runoff coefficient for occurrence probabilities of 2 and 10 years. The infiltration capacity of sedimentary rock seems to be changed by the degree of agglomeration. However, flysch (classified as sedimentary rock) has been revealed as a factor for increasing drought or flood (Gaál et al., 2012). The GLM results support the finding that the low permeability of sedimentary rock is a controlling factor in high-frequency drought.

While much research has revealed the relationship between geology and drought discharge, some researchers have claimed a stronger influence of topography than that of surface geology on groundwater level (Condon \& Maxwell, 2015). To clarify the more precise influence of geology, it is important to analyze the relationship between drought and geology under the same conditions of watershed area, topography, land use, and drought magnitude. In addition, the agglomeration degree of the rock 250 is closely related to runoff phenomena, as mentioned above. Further research is needed to quantify the relationship between drought runoff discharge and geology in various regions. 


\subsubsection{Land use factors and the drought runoff coefficient}

Changes in the number of available water resources due to an alteration of the rainfall-runoff relationship caused by vegetation changes have long been recognized (Andréassian, 2004). In addition, runoff volume differs between a coniferous forest and a broadleaf forest owing to dissimilarities in evapotranspiration (Calder 1990; Zhang et al., 2001; Hirano et al., 2009). My research results also indicate the different functions of the coniferous forest and the broadleaf forest. Based on the GLM, the broadleaf forest is selected as an increasing factor for the drought runoff coefficient for high-frequency drought, whereas the coniferous forest is a decreasing factor for low-frequency drought (Table 2). This is thought to be due to the difference in evapotranspiration. Previous research has indicated that the change in runoff volume is larger for a coniferous forest when a coniferous forest and a broadleaf forest are cleared (Bosch \& Hewlett, 1982). Further, the drought runoff volume increases due to the clearing of the coniferous forest (Andreassin, 2004; Brown et al., 2005; Maita \& Suzuki, 2007, 2008). These research results support the results of the GLM. Moreover, I presume that the reason for the coniferous forest decreasing the drought coefficient in low-frequency drought is as follows: Since evapotranspiration and canopy interception occur constantly regardless of drought magnitude, the amount of precipitation for surface runoff decreases as the precipitation amount decreases, and the effects of coniferous forests become dominant. By contrast, the evapotranspiration amount and the runoff volume are altered by the management condition of the forest, the condition of the forest floor, and tree age (Scott \& Lesch, 1997; Sakai et al., 2009; Rasoulzadeh \& Homapoor Ghoorabjiri, 2014). This research examined the relationship between the runoff coefficient and vegetation type as land use factors for relatively large watersheds. Therefore, the difference between broadleaf and coniferous forests became clear. However, it should be noted that the runoff coefficient could change even within the same forest type if the targeted watershed is smaller.

Moreover, land use change significantly alters runoff mechanisms (Fohrer et al., 2001). Among land use changes, urbanization increases flood peak discharge (Brown et al., 2009) and decrease the minimum flow (Poff et al., 2006). The main cause of urbanization decreasing the minimum flow is a decrease in the infiltration area and a decline in the base flow due to the consolidation of pipe systems (Simmons \& Reynolds, 1982; Leopold, 1968). The GLM results indicate that urban areas are a decreasing factor for the drought runoff coefficient in low-frequency drought. The composition of tree species in the forest is an important controlling factor for high-frequency drought because the source of surface water mainly depends on rainfall in the upstream area. Therefore, the impact of urbanization is assumed to be relatively low in high-frequency drought. By contrast, the surface water from the upstream area is decreased in low-frequency drought; therefore, the influence of urbanization, such as limitation of rainfall infiltration or supply of surface water from groundwater, is assumed to be dominant.

\subsubsection{Topographic factors and the drought runoff coefficient}

For the relationship between topographic factors and drought runoff, river length, watershed gradient, average watershed width, and altitude were studied as topographic factors influencing base flow (Yokoo \& Oki, 2010; Moliere et al., 2009; Engeland \& Hisdal, 2009; Castellarin et al., 2004; Abebe \& Foerch, 2006). The GLM indicated that channel slope is an 
increasing factor for the drought runoff coefficient at occurrence probabilities of 10 years or more (Table 2). This result supports the research of Moliere et al. (2009) who revealed that zero flow days increase in high-gradient rivers. However, the topographic factors were not selected as controlling factors for the drought runoff coefficient at an occurrence probability of 2 years. Runoff discharge in high-frequency drought is mainly governed by surface runoff. Therefore, the geological or land use factors closely related to surface runoff were dominant, rather than topographical factors. On the other hand, the ratio of groundwater seemed to increase with river discharge in low-frequency drought. Therefore, the topographic factor most closely related to the groundwater is thought to be selected. Moreover, this study focused on observation stations with various basin areas, including both mountainous regions and alluvial areas. Interaction between groundwater and surface water is considered to be more active in alluvial channels; therefore, the drought runoff coefficient is higher in the low-gradient watershed.

\section{Conclusions}

This manuscript reports a first attempt at revealing the relationship between drought runoff and controlling factors (geological, land use, and topographical factors) in relation to drought magnitude.

Classification results of the drought runoff coefficient across multiple drought magnitudes indicated three types of behavior for the drought runoff coefficient. The group with watersheds influenced by snowmelt runoff had a high drought runoff coefficient regardless of drought magnitude. However, the drought runoff coefficient of the group influenced by rainfall intensity decreased with increasing drought magnitude. The drought runoff coefficient of the remaining group had intermediate behavior between the aforementioned two groups. In addition, this classification result indicated a significant relationship between the ratio of plutonic rock, sedimentary rock (geological factors), urban areas, and a mixed coniferous-broadleaved forest (land use factors).

The GLM revealed that the controlling factor differs depending on drought magnitude. In high-frequency drought, the drought runoff coefficient was influenced by geological and vegetation factors, whereas land use and topographical factors influenced the drought runoff coefficient in low-frequency drought. These differences were caused by the differences in the runoff component, which dominates stream discharge in relation to drought magnitude.

This research clarified that a change in the drought runoff coefficient due to occurrence probability differs depending on precipitation pattern or climatic zone, and the controlling factors of the drought runoff coefficient changed in accordance with occurrence probability. Therefore, for effective water resource management, estimation of the drought runoff volume needs to consider precipitation pattern, geology, land use, and topography. Since the results clarify the controlling factors of drought runoff for each occurrence probability, this study contributes to effective water resource management by estimating the drought volume for climatic zones and by predicting changes in drought volume due to climate change. Further research is needed to investigate applicable climate zones and the influence of catchment scale on the relationship between drought and the controlling factors. 


\section{Competing Interests}

The author declares that he has no conflicts of interest.

\section{Acknowledgements}

This work was supported by JSPS KAKENHI grant number JP19H02250.

\section{References}

Abebe, A. and Foerch, G.: Catchment characteristics as predictors of base flow index (BFI) in Wabi-shebele river basin, East Africa. Proceedings of Conference on International Agricultural Research for Development, 1-8, 2015.

Ahmadalipour, A., Moradkhani, H., Castelletti, A., and Magliocca, N.: Future drought risk in Africa: Integrating vulnerability, climate change, and population growth. Sci. Total. Environ., 662, 672-686. 10.1016/j.scitotenv.2019.01.278, 2019.

325 Andreadis, K. M., and Lettenmaier, D. P.: Trends in 20th century drought over the continental United States. Geophys. Res. Lett., 33(10), L10403. 10.1029/2006GL025711, 2006.

Andréassian, V.: Waters and forests: From historical controversy to scientific debate. J. Hydrol., 291(1-2), 1-27. 10.1016/j.jhydrol.2003.12.015, 2004.

Arao, K., and Kaneko, K.: Regional singularities of heavy rain in June and July in Kyushu. Science bulletin of the Faculty of 330 Education, Nagasaki University, 36, 17-24, 1985.

Behrangi, A., Loikith, P. C., Fetzer, E. J., Nguyen, H. M., and Granger, S. L.: Utilizing humidity and temperature data to advance monitoring and prediction of meteorological drought. Climate, 3(4), 999-1017. https://doi.org/10.3390/cli3040999, 2015.

Bloomfield, J. P., Allen, D. J., and Griffiths, K. J.: Examining geological controls on baseflow index (BFI) using regression analysis: An illustration from the Thames Basin, UK. J. Hydrol., 373(1-2), 164-176. 10.1016/j.jhydrol.2009.04.025, 2009.

Bosch, J. M., and Hewlett, J. D. A review of catchment experiments to determine the effect of vegetation changes on water yield and evapotranspiration. J. Hydrol., 55(1-4), 3-23. 10.1016/0022-1694(82)90117-2, 1982.

Bray, J. R., and Curtis, J. T.: An Ordination of the Upland Forest Communities of Southern Wisconsin, Ecol. Monogr., 27, 325-349. https://doi.org/10.2307/1942268, 1952.

340 Brown, A. E., Zhang, L., McMahon, T. A., Western, A. W., and Vertessy, R. A.: A review of paired catchment studies for determining changes in water yield resulting from alterations in vegetation. J. Hydrol., 310(1-4), 28-61. 10.1016/j.jhydrol.2004.12.010, 2005.

Brown, L. R., Cuffney, T. F., Coles, J. F., Fitzpatrick, F., McMahon, G., Steuer, J., Bell, A. H., and May, J. T.: Urban streams across the USA: Lessons learned from studies in 9 metropolitan areas. J. N. Am. Benthol. Soc., 28(4), 1051-1069. 10.1899/08- 
Bunn, S. E., and Arthington, A. H.: Basic principles and ecological consequences of altered flow regimes for aquatic biodiversity. Environ. Manage., 30(4), 492-507. 10.1007/s00267-002-2737-0, 2002.

Burnham, K. P., and Anderson, D.R.: Model Selection and Multi-model Inference, second ed., vol. XXVI. Springer, 488, 2002. Calder, I.R: Evaporation in the Uplands. Wiley, Chichester. 148, 1990.

350 Carrão, H., Naumann, G., and Barbosa, P.: Mapping global patterns of drought risk: An empirical framework based on subnational estimates of hazard, exposure and vulnerability. Global. Environ. Change., 39, 108-124. 10.1016/j.gloenvcha.2016.04.012, 2016.

Carrão, H., Naumann, G., and Barbosa, P.: Global projections of drought hazard in a warming climate: a prime for disaster risk management. Clim. Dynam., 50(5-6), 2137-2155. 10.1007/s00382-017-3740-8, 2018.

355 Castellarin, A., Galeati, G., Brandimarte, L., Montanari, A., and Brath, A.: Regional flow-duration curves: Reliability for ungauged basins. Adv. Water. Resour., 27(10), 953-965. 10.1016/j.advwatres.2004.08.005, 2004.

Clausen, B., and Pearson, C. P.: Regional frequency analysis of annual maximum streamflow drought. J. Hydrol., 173(1-4), 111-130. 10.1016/0022-1694(95)02713-Y, 1995.

Condon, L. E., and Maxwell, R. M.: Evaluating the relationship between topography and groundwater using outputs from a 360 continental-scale integrated hydrology model. Water. Resour. Res., 51(8), 6602-6621. 10.1002/2014WR016774, 2015.

Coxon, A. P. M.: The User's Guide to Multidimensional Scaling. Heinemann, London., 1982.

Deo, R. C. Syktus, J. I., McAlpine, C. A., Lawrence, P. J., McGowan, H. A., and Phinn, S. R.: Impact of historical land cover change on daily indices of climate extremes including droughts in eastern Australia. Geophys. Res. Lett., 36(8), L08705. 10.1029/2009GL037666, 2009.

365 Eklund, L., and Seaquist, J.: Meteorological, agricultural and socioeconomic drought in the Duhok Governorate, Iraqi Kurdistan. Nat. Hazards., 76(1), 421-441. 10.1007/s11069-014-1504-x, 2015.

Eltahir, E. A. B.: Drought frequency analysis in Central and Western Sudan. Hydrolog. Sci. J., 37(3), $185-199$. 10.1080/02626669209492581, 1992.

El Kharraz, J., El-Sadek, A., Ghaffour, N., and Mino, E.: Water scarcity and drought in WANA countries. Procedia.

Engineering., 33, 14-29. 10.1016/j.proeng.2012.01.1172, 2012.

Engeland, K., and Hisdal, H.: A comparison of low flow estimates in ungauged catchments using regional regression and the HBV-model. Water. Resour. Manag., 23(12), 2567-2586. 10.1007/s11269-008-9397-7, 2009.

Fohrer, H., Haverkamp, K., Eckhardt, K., and Frede H. G.: Hydrologic response to land use changes on the catchment scale. Physics and Chemistry of the Earth, Part B: Hydrology. Oceans and Atmosphere, 26(7-8), 577-582. 10.1016/S1464375 1909(01)00052-1, 2001.

Frederiksen, H. D.: Water crisis in developing world: Misconceptions about solutions. J. Water. Res. Plan. Man., 122(2), 7987. 10.1061/(ASCE)0733-9496(1996)122:2(79), 1996. 
Gaál, L., Szolgay, J., Kohnová, S., Parajka, J., Merz, R., Viglione, A., and Blöschl, G.: Flood timescales: Understanding the interplay of climate and catchment processes through comparative hydrology. Water. Resour. Res., 48(4), W04511. 10.1029/2011WR011509, 2012.

Gauch, H. G.: Multivariate Analysis in Community Ecology. Cambridge Studies in Ecology 1. Cambridge University Press, Cambridge, 1982.

Grillakis, M. G.: Increase in severe and extreme soil moisture droughts for Europe under climate change. Sci. Total. Environ., 660, 1245-1255. 10.1016/j.scitotenv.2019.01.001, 2019.

385 Hein, A., Condon, L., and Maxwell, R.: Evaluating the relative importance of precipitation, temperature and land-cover change in the hydrologic response to extreme meteorological drought conditions over the North American High Plains. Hydrol. Earth. Syst. Sc., 23(4), 1931-1950. 10.5194/hess-23-1931-2019, 2019.

Hirano, H., Terajima, T., Nakamura, T., Sakai, M., Aoki, F., and Nanami, A.: The differences in the short-term runoff characteristics between the coniferous catchment and the deciduous catchment: the effects of storm size on stormflow generation processes of small forested catchments. Journal of Japan Society of Hydrology \& Water Resources, 22(1), 24-39. https://doi.org/10.3178/jjshwr.22.24, 2009.

Horton, R. E. Drainage Basin Characteristic, Transactions, American Geophysical Union, 13(1), 350-361, 1932.

Itsukushima, R. Tanaka, W. and Shimatani, Y.: Influence of watershed characteristics on flood discharge at 46 water level stations in Japan: findings from factor analysis at different scale of flood. Annual journal of hydraulic engineering, JSCE, 395 72(4), I_1255-I_1260. https://doi.org/10.2208/jscejhe.72.I_1255, 2016.

Kashaigili, J. J., Impacts of land-use and land-cover changes on flow regimes of the Usangu wetland and the Great Ruaha River, Tanzania. Phys. Chem. Earth., 33(8-13), 640-647. 10.1016/j.pce.2008.06.014, 2008.

Kennard, M. J., Pusey, B. J., Olden, J. D., MacKay, S. J., Stein, J. L., and Marsh, N.: Classification of natural flow regimes in Australia to support environmental flow management. Freshwater. Biol., 55(1), 171-193. 10.1111/j.1365-2427.2009.02307.x, 2010.

Kruskal, J. B.: Multidimensional scaling by optimizing goodness of fit to a nonmetric hypothesis. Psychometrika., 29(1), 127. 10.1007/BF02289565, 1964.

Lacey, G. C., and Grayson, R. B.: Relating baseflow to catchment properties in south-eastern Australia. J. Hydrol., 204(1-4), 231-250. 10.1016/S0022-1694(97)00124-8, 1998.

405 Lee, J. E., Lintner, B. R., Boyce, C. K., and Lawrence, P. J.: Land use change exacerbates tropical South American drought by sea surface temperature variability. Geophys. Res. Lett., 38(19), L19706. 10.1029/2011GL049066, 2011.

Leopold, L. B.: Hydrology for Urban Planning - A Guidebook on the Hydrologic Effects of Urban Land Use. U.S. Geological Survey Circular 554, Washington, D.C., 1968.

Liu, M., Xu, X., Xu, C., Sun, A. Y., Wang, K., Scanlon, B. R., and Zhang, L.: A new drought index that considers the joint effects of climate and land surface change. Water. Resour. Res., 53(4), 3262-3278. 10.1002/2016WR020178, 2017. 
Lytle, D. A., and Poff, N. L.: Adaptation to natural flow regimes. Trends. Ecol. Evol., 19(2), 94-100. 10.1016/j.tree.2003.10.002, 2004.

Maita, E., and Suzuki, M.: Change in the Monthly Water Yield after Clear-cutting in Fukuroyamasawa, Chiba. Journal of the Japanese Forest Society, 89(4), 278-287. https://doi.org/10.4005/jjfs.89.278, 2007.

Maita, E., and Suzuki, M.: The effect of forest cutting on flow duration curve of mountainous small watershed: evaluation of the influence of vegetation on inter-watershed variation in flow duration curve. Journal of the Japanese Forest Society, 90(1), 36-45. https://doi.org/10.4005/jjfs.90.36, 2008.

McCullagh, P., and Nelder, J.: Generalized Linear Models (second ed.), Chapman and Hall/CRC, Boca Raton, 1989.

McIntyre, N., and Marshall, M.: Identification of rural land management signals in runoff response. Hydrol. Process., 24(24), 3521-3534. 10.1002/hyp.7774, 2010.

Mehran, A., Mazdiyasni, O., and AghaKouchak, A.: A hybrid framework for assessing socioeconomic drought: Linking climate variability, local resilience, and demand. J. Geophys. Res., 120(15), 7520-7533. 10.1002/2015JD023147, 2015.

Meijerink, A. M. J.: Estimates of peak runoff from hilly terrain with varied lithology. J. Hydrol., 77(1-4), 227-236. 10.1016/0022-1694(85)90208-2, 1985.

425 Miller, V. C.: A quantitative geomorphic study of drainage basin characteristics in the Clinch mountain area, Virginia and Tennessee. J. Geol., 65(1), 30, 1953.

Mishra, A. K., and Singh, V. P.: A review of drought concepts. Journal of Hydrology, 391(1-2), 202-216. 10.1016/j.jhydrol.2010.07.012, 2010.

Moliere, D. R., Lowry, J. B. C., and Humphrey, C. L.: Classifying the flow regime of data-limited streams in the wet-dry tropical region of Australia. J. Hydrol., 367(1-2), 1-13. 10.1016/j.jhydrol.2008.12.015, 2009.

Montgomery, D. R., Dietrich, W. E., Torres, R., Anderson, S. P., Heffner, J. T., and Loague, K.: Hydrologic response of a steep, unchanneled valley to natural and applied rainfall. Water. Resour. Res., 33(1), 91-109. 10.1029/96WR02985, 1997. Mushiake, K., Takahashi, Y., and Ando, Y.: Effects of basin geology on river-flow regime in mountainous areas of Japan. Proceedings of the Japan Society of Civil Engineers, 309. 51-62. https://doi.org/10.2208/jscej1969.1981.309_51, 1981.

435 Naiman, R. J., Latterell, J. J., Pettit, N. E., and Olden, J. D.: Flow variability and the biophysical vitality of river systems. C. R. Geo. Sci., 340(9-10), 629-643. 10.1016/j.crte.2008.01.002, 2008.

Nalbantis, I., and Tsakiris, G.: Assessment of hydrological drought revisited. Water. Resour. Manag., 23(5), 881-897. 10.1007/s11269-008-9305-1, 2009.

Namias, J.: Written in the winds: the great drought of '88. Weatherwise., 42(2), 85-87. 10.1080/00431672.1989.9927088, 1989.

440 Nicholls, N.: The changing nature of Australian droughts. Climatic. Change., 63(3), $323-336$. 10.1023/B:CLIM.0000018515.46344.6d, 2004.

Nieuwolt, S.: Agricultural droughts in the tropics. Theor. Appl. Climatol., 37(1-2), 29-38. 10.1007/BF00866102, 1986.

Obled, C., Wendling, J., and Beven, K.: The sensitivity of hydrological models to spatial rainfall patterns: an evaluation using observed data. J. Hydrol., 159(1-4), 305-333. 10.1016/0022-1694(94)90263-1, 1994. 
https://doi.org/10.5194/hess-2019-330

Hydrology and

Preprint. Discussion started: 14 August 2019

(c) Author(s) 2019. CC BY 4.0 License.

Peters, E., Torfs, P. J. J. F., van Lanen, H. A. J., and Bier, G.: Propagation of drought through groundwater - A new approach using linear reservoir theory, Hydrol. Process., 17(15), 3023-3040. 10.1002/hyp.1274, 2003.

Peters, E., Van Lanen, H. A. J., Torfs, P. J. J. F., and Bier, G.: Drought in groundwater - Drought distribution and performance indicators. J. Hydrol., 306(1-4), 302-317. 10.1016/j.jhydrol.2004.09.014, 2005.

Poff, N. L., Allan, J. D., Bain, M. B., Karr, J. R., Prestegaard, K. L., Richter, B. D., Sparks, R. E., and Stromberg, J. C.: The natural flow regime: A paradigm for river conservation and restoration. Bioscience., 47(11), 769-784. 10.2307/1313099, 1997. Poff N. L., Bledsoe B. P., \& Cuhaciyan C. O.: Hydrologic variation with land use across the contiguous United States: Geomorphic and ecological consequences for stream ecosystems. Geomorphology., 79(3-4): 264-285. 10.1016/j.geomorph.2006.06.032, 2006.

Rasoulzadeh, A., and Homapoor Ghoorabjiri, M.: Comparing hydraulic properties of different forest floors. Hydrol. Process., 28(19), 5122-5130. 10.1002/hyp.10006, 2014.

Rickard, D. S.: The occurrence of agricultural drought at Ashburton, New Zealand. New. Zeal. J. Agr. Res., 3(3), 431-441. 10.1080/00288233.1960.10426627, 1960.

Sakai, Y., Hirano, T., Aoki, T., Terajima, T., and Natsuhara, Y.: The effects of tree species and forest management on the short-term runoff characteristics of the small catchments. Journal of the Japanese Society of Revegetation Technology, 35(2), 306-317. https://doi.org/10.7211/jjsrt.35.306, 2009.

Salinas, J. L., Laaha, G., Rogger, M., Parajka, J., Viglione, A., Sivapalan, M., and Blöschl, G.: Comparative assessment of predictions in ungauged basins-Part 2: Flood and low flow studies. Hydrol. Earth. Syst. Sc., 17(7), 2637-2652. 10.5194/hess17-2637-2013, 2013.

Scott, D. F., and Lesch, W.: Streamflow responses to afforestation with Eucalyptus grandis and Pinus patula and to felling in the Mokobulaan experimental catchments, South Africa. J. Hydrol., 199(3-4), 360-377. 10.1016/S0022-1694(96)03336-7, 1997.

Simmons, D. L., and Reynolds, R. J.: Effects of Urbanization on Base Flow of Selected South-Shore Streams, Long Island, New York, J. Am. Water. Resour. As., 18(5), 797-805. 10.1111/j.1752-1688.1982.tb00075.x, 1982.

Smakhtin, V. U., and Hughes, D. A.: Automated estimation and analyses of meteorological drought characteristics from monthly rainfall data. Environ. Modell. Softw., 22(6), 880-890. 10.1016/j.envsoft.2006.05.013, 2007.

Smith, A. B., and Katz, R. W.: US billion-dollar weather and climate disasters: Data sources, trends, accuracy and biases. Nat. Hazards., 67(2), 387-410. 10.1007/s11069-013-0566-5, 2013.

Smith, A. B., and Matthews, J. L.: Quantifying uncertainty and variable sensitivity within the US billion-dollar weather and climate disaster cost estimates. Nat. Hazards., 77(3), 1829-1851. 10.1007/s11069-015-1678-x, 2015.

475 Sparks, R. E.: Need for ecosystem management of large rivers and their floodplains - These phenomenally productive ecosystems produce fish and wildlife and preserve species. Bioscience., 45(3), 168-182. 10.2307/1312556, 1995.

Sudo, S.: Distribution and proportion of rock and geological layer in Japan. Aggregate resource investigation report, 56-65, 2006. 
Tabari, H., Abghari, H., and Hosseinzadeh Talaee, P.: Temporal trends and spatial characteristics of drought and rainfall in arid and semiarid regions of Iran. Hydrol. Process., 26(22), 3351-3361. 10.1002/hyp.8460, 2012.

Takahashi, Y., Kurihara, H., Kinoshira, T. Ishizaki, K., and Mushiake, K.: River hydrology. Kyoritsu Shuppan, Tokyo, 1978. Takasao, T., Takara, K., and Shimizu, A.: A basic study on frequency analysis of hydrological data in the Lake Biwa basin. Disaster Prevention Research Institute Annuals. Kyoto University, 29(B-2), 157-171, 1986.

Tallaksen, L. M., and Van Lanen, H. A. J. (Eds.): Hydrological drought: processes and estimation methods for streamflow and groundwater. In: Developments in Water Science; 48, The Netherlands, Elsevier Science B.V., Amsterdam, The Netherlands, 2004.

Taylor, C. M., Millican, D. S., Roberts, M. E., and Slack, W. T.: Long-term change to fish assemblages and the flow regime in a southeastern U.S. river system after extensive aquatic ecosystem fragmentation. Ecography., 31(6), 787-797. 10.1111/j.1600-0587.2008.05526.x, 2008.

490 Tfwala, C. M., van Rensburg, L. D., Schall, R., and Dlamini, P.: Drought dynamics and interannual rainfall variability on the Ghaap plateau, South Africa, 1918-2014. Phys. Chem. Earth., 107, 1-7. 10.1016/j.pce.2018.09.003, 2018.

Verschuren, D., Lalrd, K. R., and Cumming, B. F.: Rainfall and drought in equatorial east Africa during the past 1,100 years. Nature, 403(6768), 410-414. https://doi.org/10.1038/35000179, 2000.

Vicente-Serrano, S. M., Beguería, S., Gimeno, L., Eklundh, L., Giuliani, G., Weston, D., El Kenawy, A., López-Moreno, J. I., 495 Nieto, R., Ayenew, T., Konte, D., Ardö, J., and Pegram, G. G.S.: Challenges for drought mitigation in Africa: The potential use of geospatial data and drought information systems. App. Geogr., 34, 471-486. https://doi.org/10.1016/j.apgeog.2012.02.001, 2012.

Vogel, R. M., and Kroll, C. N.: Regional geohydrologic - geomorphic relationships for the estimation of low - flow statistics. Water. Resour. Res., 28(9), 2451-2458. 10.1029/92WR01007, 1992.

500 Wada, K., Murase, M., and Tomizawa, Y.: Study on the variation of rainfall characteristic and flood and drought risks assessment of global warming. Proceedings of JSCE. II, Hydraulic and sanitary engineering, 796, 23-37. 10.2208/jscej.2005.796_23, 2005.

Whittaker, R. J.: An application of detrended correspondence analysis and non- metric multidimensional scaling to the identification and analysis of environmental factor complexes and vegetation structures. J. Ecol., 75(2), 363-376. $50510.2307 / 2260424,1987$.

Wilhite, D. A., and Glantz, M. H.: Understanding: The drought phenomenon: The role of definitions. Water. Int., 10(3), 111120. 10.1080/02508068508686328, 1985.

Xiao-jun, W., Jian-yun, Z., Shahid, S., ElMahdi, A., Rui-min, H., Zhen-xin, B., and Ali, M.: Water resources management strategy for adaptation to droughts in China. Mitig. Adapt. Strat. G1., 17(8), 923-937. 10.1007/s11027-011-9352-4, 2012.

510 Yokoo, Y., and Oki, T.: Effects of climate, topography, soil, geology and land use on flow regimes in Japanese mountainous watersheds. Annual journal of hydraulic engineering, JSCE, 469-474, 2010. 
https://doi.org/10.5194/hess-2019-330

Preprint. Discussion started: 14 August 2019

(C) Author(s) 2019. CC BY 4.0 License.

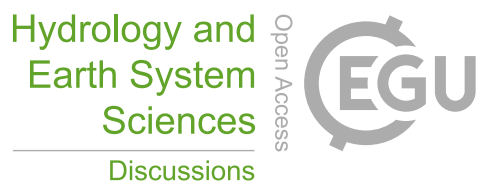

Zecharias, Y. B., and Brutsaert, W.: The influence of basin morphology on groundwater outflow. Water. Resour. Res., 24(10), 1645-1650. 10.1029/WR024i010p01645, 1988.

Zhang, L., Dawes, W. R., and Walker, G. R.: Response of mean annual evapotranspiration to vegetation changes at catchment 515 scale. Water. Resour. Res., 37(3), 701-708. 10.1029/2000WR900325, 2001. 




Figure 1: Location of the study site. The 44 observation stations in the Japanese archipelago were considered. 


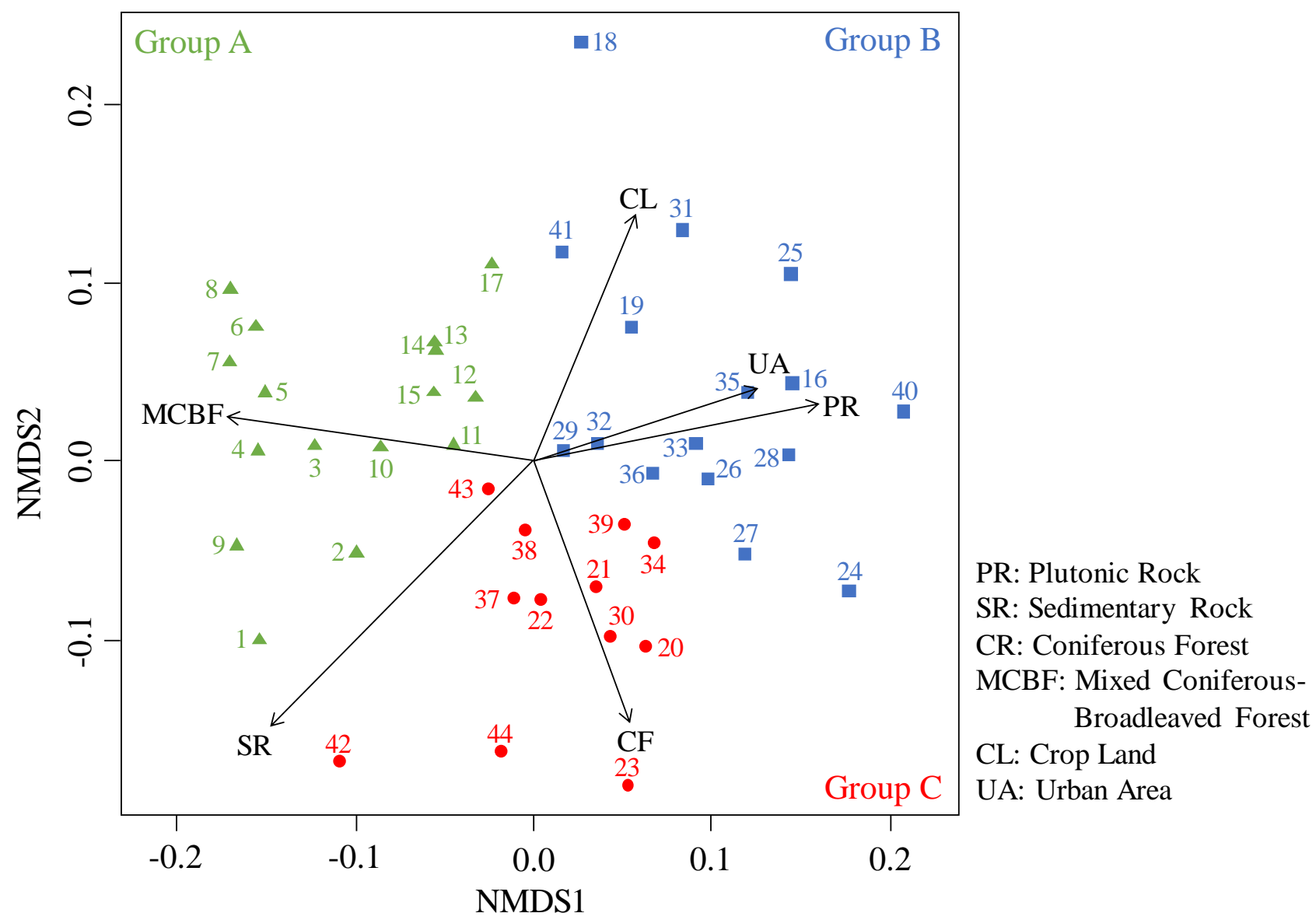

Figure 2: Results of NMDS using the drought runoff coefficient for each occurrence probability. NMDS: non-metric multidimensional scaling 


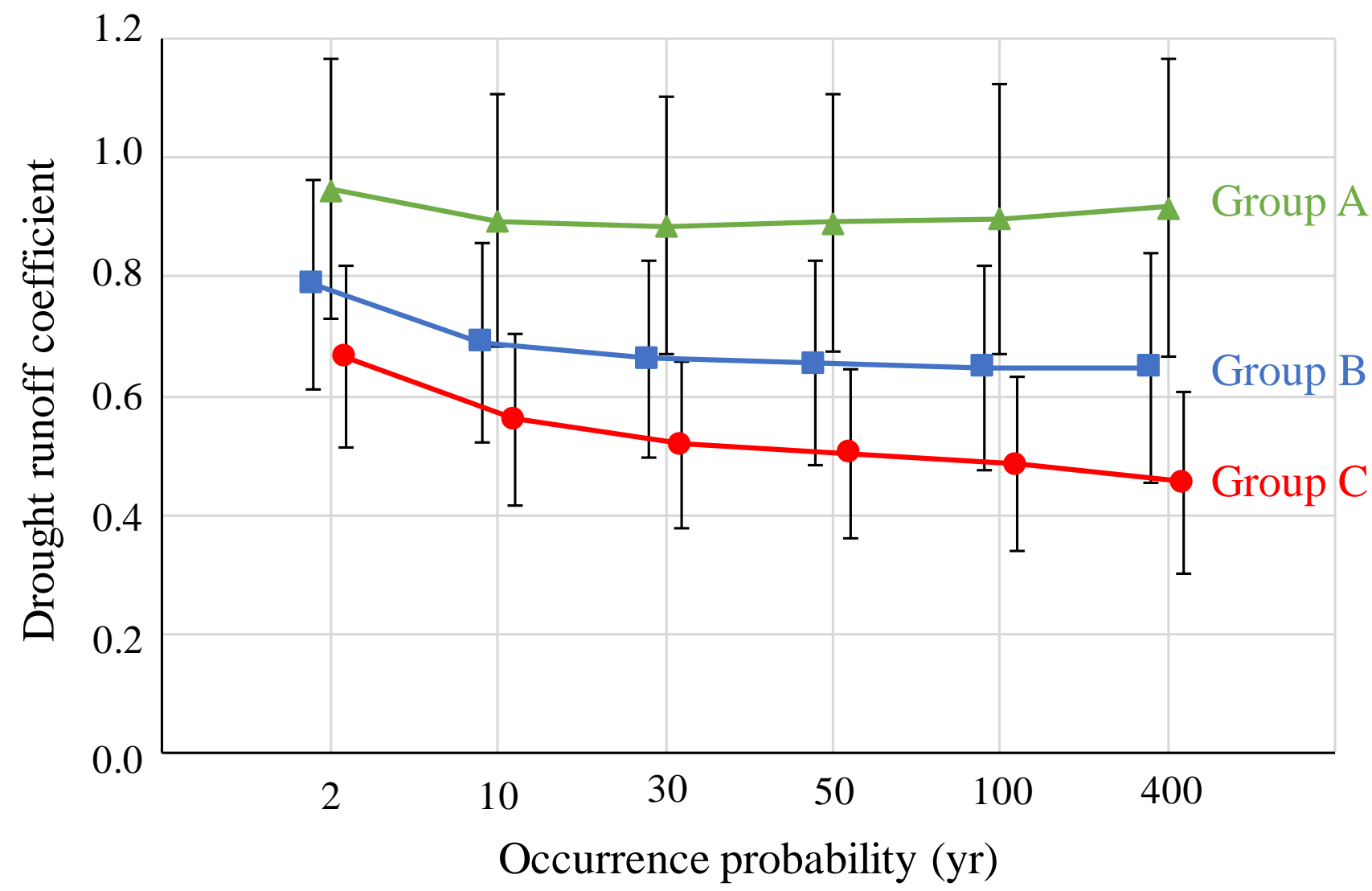

Figure 3: Average value of the drought runoff coefficient for each occurrence probability across three groups 
https://doi.org/10.5194/hess-2019-330

Preprint. Discussion started: 14 August 2019

(c) Author(s) 2019. CC BY 4.0 License.
Hydrology and Earth System Sciences

Discussions
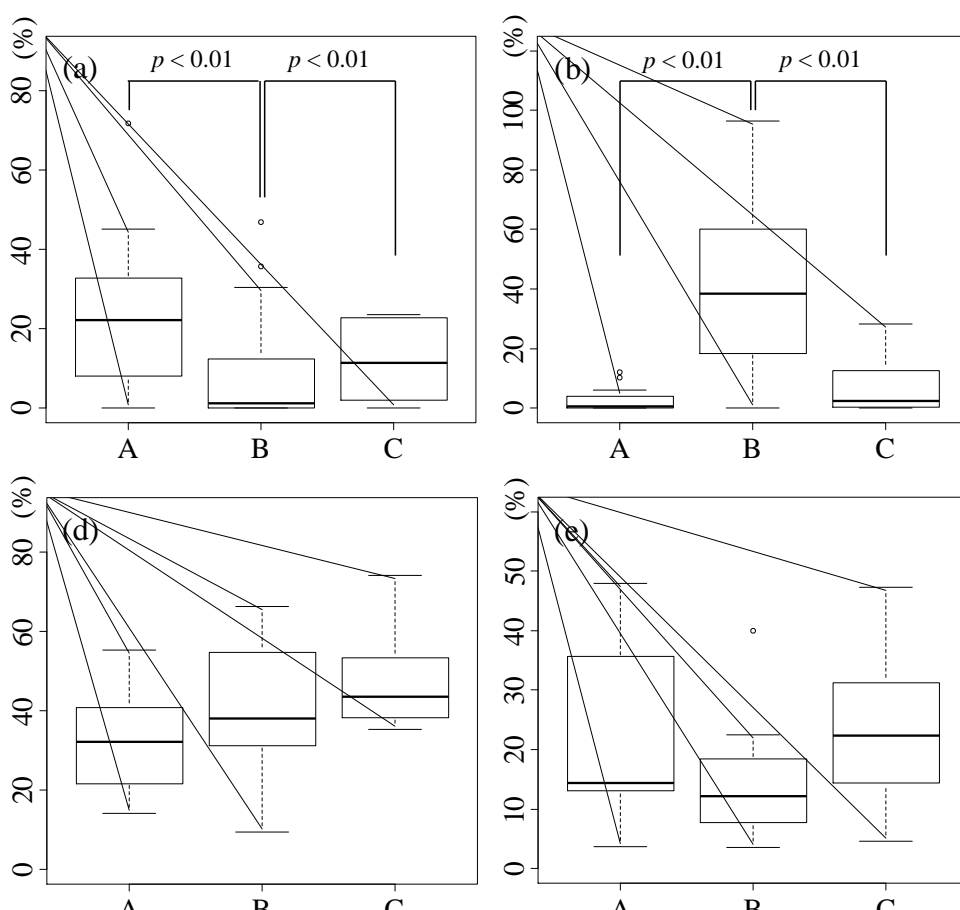

A
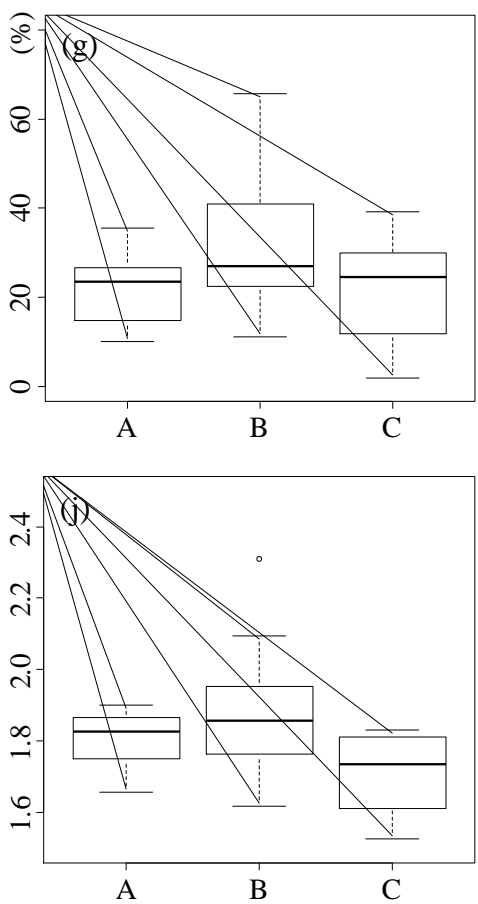

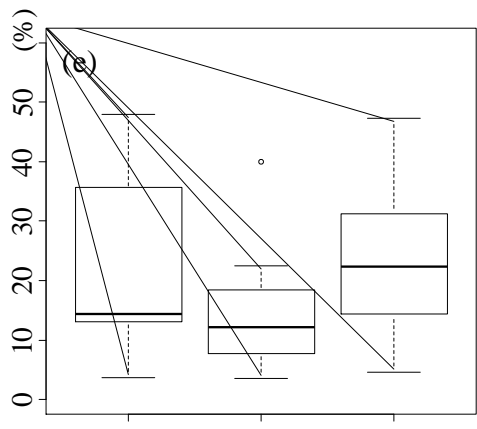

A $B \quad$ C



Figure 4: Comparison of controlling factors between groups: (a) VR: volcanic rock, (b) PR: plutonic rock, (c) SR: sedimentary rock, (d) CF: coniferous forest, (e) BF: broadleaf forest, (f) MCBF: mixed coniferous-broadleaved forest, (g) CL: crop land, (h) UA: urban area, (i) CS: channel slope, (j) TGr: topographical gradient, (k) FR: form ratio, (l) Ro: roundness 
Table 1: The calculation result of annual precipitation, drought runoff volume, and drought water volume per unit drainage area

\begin{tabular}{|c|c|c|c|c|c|c|c|c|c|c|}
\hline \multirow[t]{2}{*}{ No } & \multirow[t]{2}{*}{$\begin{array}{l}\text { Observation } \\
\text { station }\end{array}$} & \multirow[t]{2}{*}{$\begin{array}{c}\text { Basin area } \\
\left(\mathrm{km}^{2}\right)\end{array}$} & \multicolumn{6}{|c|}{$\begin{array}{c}\text { Precipitation amount for } \\
\text { each occurrence probability ( } \mathrm{mm} \text { ) }\end{array}$} & \multirow[t]{2}{*}{$\mathrm{N}$} & \multirow[t]{2}{*}{ Model } \\
\hline & & & 2 & 10 & 30 & 50 & 100 & 400 & & \\
\hline 1 & Bihoro & 824 & 925 & 731 & 659 & 633 & 602 & 554 & 31 & Gev \\
\hline 2 & Kitami & 1,394 & 794 & 601 & 515 & 481 & 439 & 370 & 31 & $\mathrm{Gev}$ \\
\hline 3 & Kaisei & 1,335 & 832 & 646 & 569 & 539 & 504 & 445 & 31 & $\mathrm{Gev}$ \\
\hline 4 & Kamishokotsu & 1,051 & 929 & 701 & 595 & 552 & 500 & 411 & 31 & Gev \\
\hline 5 & Makunbetsu & 695 & 961 & 781 & 702 & 672 & 634 & 570 & 31 & Gumbel \\
\hline 6 & Ponpira & 4,029 & 1,161 & 964 & 864 & 822 & 769 & 673 & 31 & Gev \\
\hline 7 & Uryuubashi & 1,661 & 1,439 & 1,199 & 1,085 & 1,038 & 980 & 880 & 31 & $\mathrm{Gev}$ \\
\hline 8 & Nakoma & 1,402 & 1,245 & 1,035 & 936 & 897 & 847 & 762 & 31 & LN3Q \\
\hline 9 & Mukawa & 1,228 & 1,192 & 907 & 767 & 711 & 641 & 520 & 31 & Gev \\
\hline 10 & Moiwa & 8,208 & 1,041 & 813 & 709 & 668 & 617 & 532 & 31 & LN3Q \\
\hline 11 & Takanosu & 2,109 & 1,595 & 1,285 & 1,164 & 1,120 & 1,067 & 982 & 31 & Gev \\
\hline 12 & Tsubakikawa & 4,305 & 1,957 & 1,642 & 1,522 & 1,477 & 1,422 & 1,332 & 31 & LN2LM \\
\hline 13 & Todorokibashi & 937 & 2,155 & 1,815 & 1,684 & 1,634 & 1,575 & 1,477 & 31 & LN2LM \\
\hline 14 & Sanbongibashi & 551 & 1,387 & 1,147 & 1,054 & 1,018 & 977 & 906 & 31 & Iwai \\
\hline 15 & Teratsu & 661 & 1,195 & 972 & 890 & 861 & 826 & 772 & 31 & $\mathrm{Gev}$ \\
\hline 16 & Kodaiji & 180 & 1,199 & 913 & 793 & 747 & 691 & 598 & 31 & Gev \\
\hline 17 & Shirakawa & 172 & 1,957 & 1,447 & 1,200 & 1,101 & 978 & 772 & 31 & $\mathrm{Gev}$ \\
\hline 18 & Kurogo & 580 & 977 & 774 & 685 & 651 & 608 & 536 & 31 & LN3Q \\
\hline 19 & Otome & 760 & 1,381 & 1,117 & 988 & 935 & 870 & 756 & 31 & Gev \\
\hline 20 & Nakazato & 205 & 1,629 & 1,285 & 1,103 & 1,026 & 929 & 755 & 31 & Gev \\
\hline 21 & Takatsudo & 472 & 1,684 & 1,323 & 1,149 & 1,080 & 994 & 847 & 31 & LN3Q \\
\hline 22 & Iwahana & 1,228 & 1,282 & 970 & 845 & 799 & 743 & 653 & 31 & Gumbel \\
\hline 23 & Kitamatsuno & 3,540 & 1,488 & 1,107 & 973 & 923 & 865 & 772 & 31 & Iwai \\
\hline 24 & Iwakura & 501 & 1,634 & 1,266 & 1,117 & 1,060 & 992 & 877 & 31 & Iwai \\
\hline 25 & Hota & 163 & 1,337 & 907 & 717 & 646 & 564 & 434 & 31 & LN3Q \\
\hline 26 & Banjou & 105 & 1,372 & 1,037 & 862 & 790 & 700 & 544 & 31 & Gev \\
\hline 27 & Kashiwara & 962 & 1,397 & 1,035 & 866 & 800 & 720 & 589 & 31 & LN3Q \\
\hline 28 & Hirohara & 195 & 1,869 & 1,616 & 1,520 & 1,484 & 1,443 & 1,381 & 31 & Gev \\
\hline 29 & Huichiba & 837 & 1,721 & 1,412 & 1,287 & 1,239 & 1,181 & 1,082 & 31 & LogP3 \\
\hline 30 & Mitani & 1,049 & 1,818 & 1,435 & 1,307 & 1,261 & 1,208 & 1,122 & 31 & LP3Rs \\
\hline 31 & Otsu & 911 & 1,866 & 1,536 & 1,401 & 1,348 & 1,282 & 1,172 & 31 & LogP3 \\
\hline 32 & Miyatabashi & 123 & 1,475 & 1,112 & 950 & 886 & 808 & 677 & 31 & Gev \\
\hline 33 & Natsuyoshi & 47 & 1,890 & 1,404 & 1,178 & 1,087 & 977 & 791 & 31 & $\mathrm{Gev}$ \\
\hline 34 & Nakashima & 326 & 2,262 & 1,664 & 1,379 & 1,264 & 1,125 & 891 & 31 & $\mathrm{Gev}$ \\
\hline 35 & Akimatsubashi & 113 & 1,835 & 1,368 & 1,144 & 1,055 & 944 & 756 & 31 & $\mathrm{Gev}$ \\
\hline 36 & Hinodebashi & 695 & 1,751 & 1,309 & 1,101 & 1,018 & 917 & 745 & 31 & $\mathrm{Gev}$ \\
\hline 37 & Tokusuebashi & 71 & 2,252 & 1,531 & 1,256 & 1,159 & 1,049 & 883 & 31 & Exp \\
\hline 38 & Kawanishibashi & 120 & 2,252 & 1,618 & 1,323 & 1,205 & 1,063 & 824 & 31 & $\mathrm{Gev}$ \\
\hline 39 & Myokenbashi & 95 & 1,825 & 1,342 & 1,115 & 1,024 & 912 & 725 & 31 & Gev \\
\hline 40 & Ikemori & 231 & 1,748 & 1,271 & 1,037 & 943 & 826 & 632 & 31 & Gev \\
\hline 41 & Tateno & 386 & 2,688 & 1,992 & 1,727 & 1,629 & 1,511 & 1,316 & 31 & $\log \mathrm{P} 3$ \\
\hline 42 & Itsukimiyazono & 227 & 2,217 & 1,639 & 1,414 & 1,330 & 1,232 & 1,068 & 31 & LN3Q \\
\hline 43 & Shiratakibashi & 1,381 & 1,942 & 1,441 & 1,247 & 1,174 & 1,087 & 943 & 31 & LogP3 \\
\hline 44 & Banjyoubashi & 278 & 2,165 & 1,548 & 1,321 & 1,238 & 1,142 & 989 & 31 & Gumbel \\
\hline
\end{tabular}


Table 1: (Continued)

\begin{tabular}{|c|c|c|c|c|c|c|c|c|c|c|c|c|c|c|}
\hline \multirow[t]{2}{*}{ No } & \multicolumn{6}{|c|}{$\begin{array}{c}\text { Drought water volume for } \\
\text { each occurrence probability }\left(10^{6} \mathrm{~m}^{3}\right)\end{array}$} & \multirow[t]{2}{*}{$\mathrm{N}$} & \multirow[t]{2}{*}{ Model } & \multicolumn{6}{|c|}{$\begin{array}{l}\text { Drought water volume per unit drainage } \\
\text { area for each occurrence probability }\end{array}$} \\
\hline & 2 & 10 & 30 & 50 & 100 & 400 & & & 2 & 10 & 30 & 50 & 100 & 400 \\
\hline 1 & 435 & 299 & 254 & 240 & 222 & 196 & 60 & $\mathrm{Gev}$ & 0.53 & 0.36 & 0.31 & 0.29 & 0.27 & 0.24 \\
\hline 2 & 699 & 521 & 461 & 441 & 415 & 373 & 60 & LN3PM & 0.50 & 0.37 & 0.33 & 0.32 & 0.30 & 0.27 \\
\hline 3 & 962 & 709 & 637 & 613 & 585 & 541 & 52 & LogP3 & 0.72 & 0.53 & 0.48 & 0.46 & 0.44 & 0.40 \\
\hline 4 & 909 & 680 & 610 & 588 & 565 & 532 & 60 & Gev & 0.86 & 0.65 & 0.58 & 0.56 & 0.54 & 0.51 \\
\hline 5 & 833 & 588 & 500 & 476 & 435 & 385 & 49 & LN3Q & 1.20 & 0.85 & 0.72 & 0.69 & 0.63 & 0.55 \\
\hline 6 & 5,882 & 4,762 & 4,348 & 4,167 & 4,000 & 3,704 & 46 & Gev & 1.46 & 1.18 & 1.08 & 1.03 & 0.99 & 0.92 \\
\hline 7 & 2,326 & 1,852 & 1,667 & 1,587 & 1,515 & 1,370 & 40 & LN3Q & 1.40 & 1.11 & 1.00 & 0.96 & 0.91 & 0.82 \\
\hline 8 & 2,082 & 1,724 & 1,613 & 1,563 & 1,515 & 1,449 & 52 & $\mathrm{Gev}$ & 1.49 & 1.23 & 1.15 & 1.11 & 1.08 & 1.03 \\
\hline 9 & 1,250 & 833 & 667 & 625 & 556 & 438 & 42 & LogP3 & 1.02 & 0.68 & 0.54 & 0.51 & 0.45 & 0.35 \\
\hline 10 & 7,143 & 5,263 & 4,545 & 4,348 & 4,000 & 3,448 & 47 & $\log \mathrm{P} 3$ & 0.87 & 0.64 & 0.55 & 0.53 & 0.49 & 0.42 \\
\hline 11 & 3,226 & 2,632 & 2,381 & 2,283 & 2,174 & 2,000 & 55 & Iwai & 1.53 & 1.25 & 1.13 & 1.08 & 1.03 & 0.95 \\
\hline 12 & 8,333 & 6,667 & 5,882 & 5,882 & 5,556 & 5,263 & 71 & $\mathrm{Gev}$ & 2.07 & 1.65 & 1.46 & 1.46 & 1.38 & 1.30 \\
\hline 13 & 1,961 & 1,538 & 1,389 & 1,333 & 1,266 & 1,149 & 43 & LN3PM & 2.09 & 1.64 & 1.48 & 1.42 & 1.35 & 1.23 \\
\hline 14 & 877 & 676 & 610 & 585 & 559 & 513 & 41 & Iwai & 1.59 & 1.23 & 1.11 & 1.06 & 1.01 & 0.93 \\
\hline 15 & 833 & 625 & 526 & 500 & 476 & 400 & 42 & Gumbel & 1.26 & 0.95 & 0.80 & 0.76 & 0.72 & 0.61 \\
\hline 16 & 137 & 95 & 83 & 78 & 72 & 65 & 36 & $\mathrm{Gev}$ & 0.76 & 0.53 & 0.46 & 0.43 & 0.40 & 0.36 \\
\hline 17 & 196 & 137 & 116 & 110 & 101 & 88 & 48 & Gev & 1.14 & 0.80 & 0.68 & 0.64 & 0.59 & 0.51 \\
\hline 18 & 714 & 526 & 455 & 435 & 400 & 357 & 55 & Gumbel & 1.23 & 0.91 & 0.78 & 0.75 & 0.69 & 0.62 \\
\hline 19 & 1,064 & 690 & 524 & 461 & 388 & 274 & 36 & Gev & 1.40 & 0.91 & 0.69 & 0.61 & 0.51 & 0.36 \\
\hline 20 & 217 & 141 & 110 & 98 & 84 & 62 & 37 & $\mathrm{Gev}$ & 1.06 & 0.69 & 0.53 & 0.48 & 0.41 & 0.30 \\
\hline 21 & 588 & 370 & 286 & 263 & 227 & 182 & 51 & LN3Q & 1.25 & 0.78 & 0.61 & 0.56 & 0.48 & 0.39 \\
\hline 22 & 901 & 592 & 478 & 439 & 392 & 318 & 42 & Gev & 0.73 & 0.48 & 0.39 & 0.36 & 0.32 & 0.26 \\
\hline 23 & 2,174 & 1,163 & 885 & 794 & 699 & 552 & 49 & LN3Q & 0.61 & 0.33 & 0.25 & 0.22 & 0.20 & 0.16 \\
\hline 24 & 500 & 314 & 240 & 214 & 182 & 133 & 42 & Gev & 1.00 & 0.63 & 0.48 & 0.43 & 0.36 & 0.27 \\
\hline 25 & 200 & 118 & 94 & 86 & 78 & 65 & 24 & Gumbel & 1.23 & 0.72 & 0.58 & 0.53 & 0.48 & 0.40 \\
\hline 26 & 102 & 64 & 52 & 48 & 43 & 36 & 29 & Gumbel & 0.97 & 0.61 & 0.49 & 0.46 & 0.41 & 0.35 \\
\hline 27 & 840 & 552 & 446 & 410 & 369 & 308 & 29 & Exp & 0.87 & 0.57 & 0.46 & 0.43 & 0.38 & 0.32 \\
\hline 28 & 278 & 213 & 189 & 180 & 169 & 154 & 35 & Iwai & 1.42 & 1.09 & 0.97 & 0.93 & 0.87 & 0.79 \\
\hline 29 & 1,205 & 943 & 855 & 820 & 781 & 719 & 32 & LP3Rs & 1.44 & 1.13 & 1.02 & 0.98 & 0.93 & 0.86 \\
\hline 30 & 1,282 & 862 & 704 & 649 & 581 & 474 & 28 & $\mathrm{Gev}$ & 1.22 & 0.82 & 0.67 & 0.62 & 0.55 & 0.45 \\
\hline 31 & 1,389 & 1,064 & 935 & 885 & 826 & 730 & 23 & Gumbel & 1.52 & 1.17 & 1.03 & 0.97 & 0.91 & 0.80 \\
\hline 32 & 141 & 93 & 79 & 74 & 68 & 60 & 58 & $\log \mathrm{P} 3$ & 1.15 & 0.76 & 0.64 & 0.60 & 0.56 & 0.49 \\
\hline 33 & 76 & 46 & 35 & 31 & 26 & 19 & 30 & Gev & 1.61 & 0.98 & 0.74 & 0.65 & 0.55 & 0.39 \\
\hline 34 & 412 & 260 & 207 & 188 & 167 & 134 & 62 & SqrtEt & 1.26 & 0.80 & 0.64 & 0.58 & 0.51 & 0.41 \\
\hline 35 & 156 & 102 & 84 & 78 & 71 & 60 & 38 & Gumbel & 1.38 & 0.90 & 0.74 & 0.69 & 0.63 & 0.53 \\
\hline 36 & 952 & 595 & 469 & 426 & 376 & 300 & 55 & SqrtEt & 1.37 & 0.86 & 0.68 & 0.61 & 0.54 & 0.43 \\
\hline 37 & 96 & 58 & 45 & 41 & 36 & 28 & 41 & SqrtEt & 1.35 & 0.82 & 0.64 & 0.57 & 0.50 & 0.40 \\
\hline 38 & 185 & 106 & 81 & 71 & 61 & 46 & 38 & Gev & 1.54 & 0.89 & 0.67 & 0.60 & 0.51 & 0.38 \\
\hline 39 & 133 & 78 & 56 & 48 & 38 & 25 & 27 & Gev & 1.40 & 0.82 & 0.59 & 0.50 & 0.40 & 0.26 \\
\hline 40 & 222 & 133 & 109 & 101 & 93 & 80 & 25 & Gev & 0.96 & 0.58 & 0.47 & 0.44 & 0.40 & 0.35 \\
\hline 41 & 714 & 500 & 435 & 400 & 370 & 323 & 24 & Gumbel & 1.85 & 1.30 & 1.13 & 1.04 & 0.96 & 0.84 \\
\hline 42 & 526 & 345 & 278 & 256 & 233 & 192 & 35 & LN3Q & 2.32 & 1.52 & 1.22 & 1.13 & 1.02 & 0.85 \\
\hline 43 & 1,818 & 1,282 & 1,124 & 1,064 & 1,000 & 893 & 66 & LN3PM & 1.32 & 0.93 & 0.81 & 0.77 & 0.72 & 0.65 \\
\hline 44 & 357 & 209 & 165 & 150 & 133 & 108 & 57 & LN3Q & 1.28 & 0.75 & 0.59 & 0.54 & 0.48 & 0.39 \\
\hline
\end{tabular}


https://doi.org/10.5194/hess-2019-330

Hydrology and

Preprint. Discussion started: 14 August 2019

(c) Author(s) 2019. CC BY 4.0 License.

535 Table 2: Analysis of the relationship between drought runoff coefficient of each occurrence probability and controlling factors by GLM

\begin{tabular}{|c|c|c|c|c|c|c|}
\hline & \multicolumn{6}{|c|}{ Occurrence probability } \\
\hline & 2 & 10 & 30 & 50 & 100 & 400 \\
\hline \multicolumn{7}{|c|}{ Geological factor } \\
\hline \multicolumn{7}{|l|}{ VR } \\
\hline PR & $(-) * *$ & $(-) *$ & & & & \\
\hline SR & $(-) * *$ & $(-) * *$ & & & & \\
\hline \multicolumn{7}{|c|}{ Land use factor } \\
\hline $\mathrm{BF}$ & $(+) *$ & $(+) * *$ & & & & \\
\hline $\mathrm{CF}$ & & & $(-) * *$ & $(-) * * *$ & $(-) * *$ & $(-) * * *$ \\
\hline $\mathrm{MCBF}$ & $(+) * *$ & $(+) * *$ & & & & \\
\hline $\mathrm{CL}$ & & & & $(-) *$ & & \\
\hline UA & & & $(-) *$ & $(-) *$ & $(-) *$ & $(-) *$ \\
\hline \multicolumn{7}{|c|}{ Topographical factor } \\
\hline $\mathrm{CS}$ & & $(+) * *$ & $(+) * *$ & $(+) * *$ & $(+) *$ & $(+) *$ \\
\hline \multicolumn{7}{|l|}{ FR } \\
\hline \multicolumn{7}{|l|}{ RO } \\
\hline$\overline{\mathrm{R}^{2}}$ & 0.377 & 0.441 & 0.435 & 0.444 & 0.421 & 0.430 \\
\hline AIC & -23.013 & -24.676 & -20.005 & -17.291 & -12.615 & -4.9517 \\
\hline
\end{tabular}

